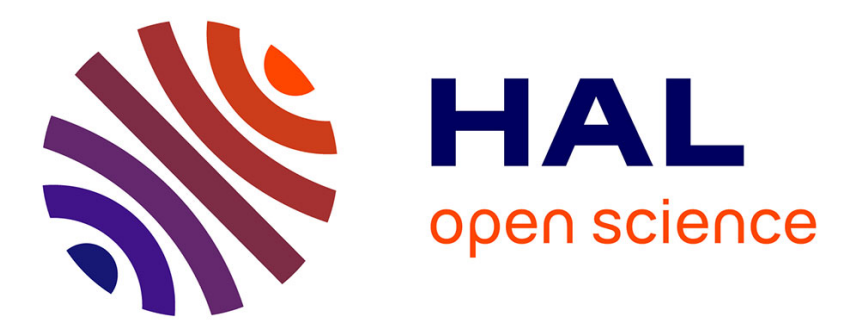

\title{
Influence of the composition of PMMA nanocomposites on gaseous effluents emitted during combustion
}

\author{
Carine Chivas-Joly, Claire Longuet, Charles Motzkus, José-Marie
}

Lopez-Cuesta

\section{- To cite this version:}

Carine Chivas-Joly, Claire Longuet, Charles Motzkus, José-Marie Lopez-Cuesta. Influence of the composition of PMMA nanocomposites on gaseous effluents emitted during combustion. Polymer Degradation and Stability, 2015, 113 (SI), pp.197-207. 10.1016/j.polymdegradstab.2014.11.015 . hal02914239

\author{
HAL Id: hal-02914239 \\ https://hal.science/hal-02914239
}

Submitted on 25 May 2021

HAL is a multi-disciplinary open access archive for the deposit and dissemination of scientific research documents, whether they are published or not. The documents may come from teaching and research institutions in France or abroad, or from public or private research centers.
L'archive ouverte pluridisciplinaire HAL, est destinée au dépôt et à la diffusion de documents scientifiques de niveau recherche, publiés ou non, émanant des établissements d'enseignement et de recherche français ou étrangers, des laboratoires publics ou privés. 


\title{
Influence of the composition of PMMA nanocomposites on gaseous effluents emitted during combustion
}

\author{
Carine Chivas-Joly ${ }^{\text {a, }}{ }^{*}$, Claire Longuet ${ }^{\mathrm{b}}$, Charles Motzkus ${ }^{\mathrm{a}}$, José-Marie Lopez-Cuesta ${ }^{\mathrm{b}}$ \\ ${ }^{a}$ Laboratoire National de métrologie et d'Essais (LNE), 78197 Trappes Cedex, France \\ ${ }^{\mathrm{b}}$ Ecole des Mines d'Alès, Centre des Matériaux (C2MA), 6 Avenue de Clavières, 30319 Alès Cedex, France
}

\begin{abstract}
A B S T R A C T
This paper focuses on the nature of thermal degradation products formed by combustion of various PMMA nanocomposites and on the kinetics of emission of gases emitted during combustion. Compositions of two kinds of nanosilica and nanoalumina and their combinations with Ammonium PolyPhosphate (APP) in PMMA were prepared. Their thermal degradation was carried out using TGA coupled with FTIR and cone calorimeter. For the compositions of nanooxides, it appears that the kinetics of emission of gases is significantly influenced by the nature of oxide and by the surface treatment, but mainly for silica. Octylsilane modified silica combined with APP leads to an outstanding fire behaviour, due to the formation of a very cohesive and expanded layer containing silicon pyrophosphate, but at the expense of a higher $\mathrm{CO}$ emission and a measurable emission of HCN. Even if the presence of fire retardant (APP) and the incorporation of nanosilica with a surface treatment reduce the flammability, the high value of the $\mathrm{CO}$ yield could lead to the conclusion that the combination could improve toxicity. But, the nanocomposite based on silica surface treatment coupled with APP, induce a delay of the CO yield emission, which could allow people to evacuate buildings or houses in case of fire.
\end{abstract}

Keywords:

Nanoparticles

Cone calorimeter

FTIR

Emission yields

Kinetics of gases

\section{Introduction}

In current flame retardant materials research, the use of nanoobjects is in constant evolution, because they can impart better physical and chemical properties such as mechanical, electrical, thermophysical ones as well as fire behaviour to polymers. However, in order to meet fire retardancy standards, nano-objects cannot be used alone and combinations with flame retardants have to be used. Hence, several combinations of nano-objects (or nanoparticles) and FR additives have been investigated for various polymers in order to achieve synergistic effects on fire performance [1]. Carbon nanotubes (CNT) and nano-oxides offer an enormous potential for development of new materials and products, and represent a significant part of the quickly growing nanocomposite

Abbreviations: APP, ammonium polyphosphate; CC, cone calorimeter; FR, flame retardant; FTIR, fourier transform infrared spectroscopy; HRR, heat release rate; PMMA, poly(methyl methacrylate); ST, surface treatment; STEM, scanning transmission electron microscopy; TGA, thermogravimetric analysis; XRD, X-ray diffraction.

* Corresponding author.

E-mail address: carine.chivas-joly@Ine.fr (C. Chivas-Joly). economy. Products underpinned by nanotechnologies are forecast to grow from a global volume of $€ 200$ billion in 2009 to $€ 2$ trillion by 2015 [2]. Poly(methyl methacrylate) (PMMA) is one of the most widely used thermoplastics. The global poly(methyl methacrylate) market revenue is estimated to $\$ 6.6$ billion in 2011 [3]. But as it is a highly flammable polymer, its use in many applications is limited. During the past decade, the incorporation of flame retardant with different types of nano-objects into PMMA via melt blending or in situ polymerization has been investigated in order to improve its flammability. The mechanism of thermal degradation of PMMA, regarding its synthesis mode (anionic or radicalar) and the presence of structure defects has been widely studied by various authors [4-13]. Various mechanisms have been proposed to explain the influence of oxygen during thermal degradation. Brown and Kashiwagi [4] showed that in oxidizing atmosphere the depolymerization of PMMA occurs at lower temperatures than in inert atmosphere because of random scissions of macromolecules catalysed by oxygen, which initiate depolymerisation. Nevertheless, the same authors [11] have shown later that oxygen could act on unsaturated chain ends by forming a more stable hydroxyl end group. From all these works, it can be concluded that oxygen favours the random scission of the main chain, leading to an acceleration of 
depolymerisation via radicals. The stabilizing effect of oxygen concerns only radicals coming from chain ends decomposition and thereby it is not effective for PMMA having chain ends yet stabilized or PMMA synthesized through anionic polymerization.

In order to improve thermal stability as well as fire retardancy of PMMA, strategies involving nanoparticles have been implemented. For example, the interest of the incorporation of CNTs in PMMA to improve fire reaction has been shown by Kashiwagi et al. [14]. A significant decrease in peak of heat release rate at cone calorimeter test was highlighted for CNT percentages less than 1wt\%.

Various authors have also shown the interest of nano-silica, zirconium, zinc, iron, cerium, titanium, vanadium or nanooxides on thermal stability and in some cases on fire retardancy of PMMA for loadings up to $20 \%$ [15-26].

Improvement of both thermal stability and fire reaction was shown, in particular by Laachachi et al., using nano- $\mathrm{TiO}_{2},-\mathrm{Al}_{2} \mathrm{O}_{3}$, $-\mathrm{Fe}_{2} \mathrm{O}_{3}[25,26]$ and Cinausero et al. $[26,27]$ using nano- $\mathrm{SiO}_{2}$ and nano- $\mathrm{Al}_{2} \mathrm{O}_{3}$. On the whole, it was shown that from $5 \%$ wt of nanooxides, the thermal stability studied using TGA increased. In addition, significant reduction in HRR values were observed, the lowest pHRR values being obtained for 20wt\% of nanooxides.

Various authors have highlighted mechanisms based on interactions between the surface groups of oxides and the polar groups of PMMA (Fig. 1) [28,29]. Acid-base or ionic Interactions involve surface groups of the alumina on the one hand, and the carbonyl groups and methoxy PMMA on the other hand. This would lead to strong bonds (ionic, covalent) that participate in the stabilization of the nanocomposite during thermal degradation and delay the depolymerisation.

Thus, alumina would act in the process of stabilization by a stabilizing effect on the thermo-chemical degradation of the PMMA, and indirectly by an antioxidant action.

a)

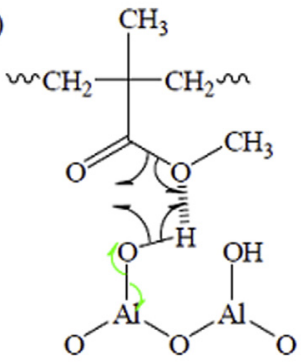

Reaction with the acid sites

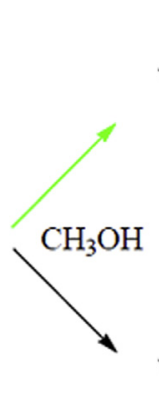<smiles></smiles><smiles>CCC(C)(CC)C(=O)O[Al]([O-])O[Al](O)O</smiles>

b)

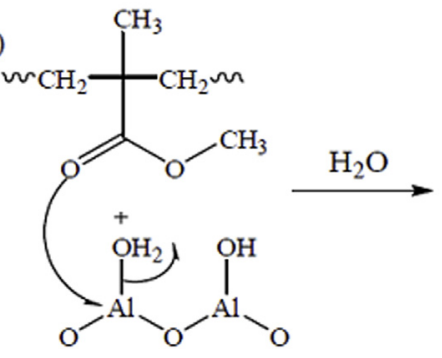<smiles>CCC(C)(CC)C(=O)O[Al](O)O[Al](O)O</smiles>

Reaction with the basic sites

Fig. 1. Thermal degradation mechanism of polyacrylate/ZnO nanocomposites based on Liufu et al.[28].
Nevertheless, it has been shown that the use of nanooxides alone was not enough to meet standards requirements for many applications. Hence, combinations of nanooxides with flame retardants such as phosphorous ones have been carried out by several authors [24,27,30-32]. A part of these studies concerns combinations of nanooxides with Ammonium PolyPhosphate (APP) and more recently, Quach et al. [33] have shown the efficiency of a surface treatment by octylsilane of silica nanoparticles in combination with phosphorous fire retardant additives on the fire retardancy of PMMA investigated using cone calorimeter at an irradiance of $50 \mathrm{~kW} / \mathrm{m}^{2}$. As in the previous work of Cinausero et al. [27], the authors noticed the formation of silicon phosphate $\left(\mathrm{SiP}_{2} \mathrm{O}_{7}\right)$ in the residues and concluded that the formation of these compounds during combustion allows synergistic effects on fire retardancy to be achieved, through the formation of a cohesive protective layer. High level of reactivity to form these compounds was also ascribed to the huge specific surface area of nanoparticles. Cinausero et al. [27] have shown the formation of aluminium phosphates when nanoalumina was combined with APP.

Recently, Motzkus et al. [34] described the fire behaviour and investigated the solid and aerosol effluents of thermoplastic polymers (PMMA, PA-6), filled with nanoparticles (CNTs, nano-silica, nano-alumina) used to improve their flame retardancy. In this study, an experimental setup was developed to measure the mass distribution in the [30 nm-10 $\mu \mathrm{m}$ ] range and the concentration of particles in the aerosol. Comparisons were made between unfilled and filled polymers and the influence of filler surface treatments as well as the combinations with a flame retardant investigated. The presence of nano-oxides in the polymers shows a significant effect on the rate of particle emission and the concentration of the emitted submicron particles. The comparisons of mass distributions of aerosol emitted during the combustion of various formulations show that in the case of the PMMA with and without $\mathrm{SiO}_{2}$ and $\mathrm{Al}_{2} \mathrm{O}_{3}$ nanooxides, the large mass quantities of particles emitted corresponded to submicrometric particles (close to $80 \%$ ) and ultra-fine particles (close to 20\%). Paradoxically, the presence of nanoparticles in the PMMA influences significantly the rate of particle emission with a decrease in the number concentration of the submicrometric particles emitted. The influence of a silane surface treatment on the nanofillers can involve a decrease of the number concentration of submicrometric particles. The addition of a flame retardant (APP: ammonium polyphosphate) leads to a strong increase of the number concentration of particles emitted, but nano-oxides alone such as $\mathrm{Al}_{2} \mathrm{O}_{3}$, are unable to cause a significant increase in the number concentration of fine particles emitted $(<1 \mu \mathrm{m})$.

The influence of the flame retardant systems containing APP on aerosols leads to the presence of droplets, which appears as circular shapes with very sharp and well-defined edges and a very high contrast revealing a change in material stiffness. The presence of aggregates stuck in droplets and droplet coalescence appears to show that droplets are very soft, maybe tars or liquid phases. Rhodes et al. [35] have been studied the particle size distribution in polyamide-6 (PA-6) + flame retardants (FR) + nanofibers using a Tubular furnace as Fire model. The main results prove the high level of small particles $(<0.5 \mu \mathrm{m})$ with additives. This is compliant with our previous work with APP [34]. The role of the presence of nanoobjects used as fillers, reinforcements or FR systems components has been taken into account on toxicity, smoke and particle emissions only recently.

As mentioned above, to improve fire performance, flameretardants and nanoparticles are frequently combined in polymers, possibly leading to modifications in the composition of fire effluents, and thereby to the evolution of the potential toxic character of gases. In this paper, thermal degradation (ATG/FTIR) and 
gaseous effluents (CC/FTIR) of polymethylmethacrylate (PMMA) filled with nano-objects (silica, alumina) and ammonium polyphosphate (APP) used to improve flame retardancy were investigated.

This study describes the measurements of yields of smoke and toxic components of fire effluents from pristine PMMA, filled PMMA and the influence of surface treatments (silane-based), as well as the combination with a flame retardant (ammonium polyphosphate (APP)). Fire effluents $\left(\mathrm{CO}, \mathrm{CO}_{2}, \mathrm{HCN}, \mathrm{NO}_{x} \ldots\right)$ were generated using a cone calorimeter [36] coupled with an FTIR [37]. We will particularly focus on highlighting the influence of nanoobjects on mechanisms of thermal degradation and gaseous effluents, to weigh the various impacts of the introduction of these nanofillers. This paper focuses particularly on the first step concerning fire effluents and modifications of the combustion chemistry (new species of effluents, modification of thermal and chemical release). The results will be correlated with the gaseous measurement on PMMA carried out versus nanofillers. It is expected these elements will give conclusions regarding the environmental, health and safety aspects of nanocomposites burning during accidental conditions.

\section{Experiments}

\subsection{Materials}

In this study, powder of poly(methyl methacrylate), PMMA, (Altuglas BS9ELS) was kindly given by Arkema (Serquigny, France). A PMMA masterbatch containing 5 wt.\% of multi-wall carbon nanotubes (MWCNT), and the same PMMA without nano-objects, were kindly supplied by Arkema. These materials were processed mechanically mixed prior to feeding the extruder to prepare PMMA containing $1 \% \mathrm{wt}$. MWCNT. Other nanocomposites were prepared by mixing PMMA powder with silica or alumina nanoparticles each formulation containing $15 \mathrm{wt}$ \% of inorganic filler with and without octylsilane surface treatment. Compositions of each nanoparticles (5 wt.\%) combined with APP additive (10 wt.\%) were also prepared. The processing and various aspects of characterization of these materials have been reported in detail in Cinausero et al. [27] and Quach et al. [33]. Table 1 presents the list of compositions used and characteristics of nanoparticles. The study of the dispersion of nano-objects of all compositions enabled to conclude that the silica and the alumina were better dispersed than MWNT in PMMA and that nanoparticles with octylsilane surface treatment led to the best dispersion. In addition, Fig. 2 represents our observations with and without the incorporation of a flame retardant (APP). The comparison of compositions led us to conclude that the addition of APP with alumina, with or without treatment, degrades the dispersion of particles, while in the case of treated silica APP, it seems to improves it.

\subsection{Experimental techniques}

This section describes the experimental set up and measurements devoted to determine experimentally the decomposition products of nanocomposites.

\subsubsection{Cone calorimeter coupled with FTIR}

In these experiments, cone calorimeter test (ISO 5660, [36]) was performed at an incident radiant flux of $50 \mathrm{~kW} / \mathrm{m}^{2}$ using a Fire Testing Technology apparatus, coupled with FTIR spectrometer, (ISO 19702, [37]), in order to detect the evolved gases. PMMA formulations of thermal degradation products were determined and quantified on-line all along the experiment using the following apparatus (FTIR Thermo Fischer Magna 550). Experimental conditions were $10 \mathrm{~m}$ path length, $2 \mathrm{~L}$ gas cell operated at $180^{\circ} \mathrm{C}$ and 650 torr. Detection was performed with an MCT-A detector, and quantification by the least squares method, in comparison with standard spectra made by LNE.

\subsubsection{TGA coupled with FTIR}

TGA experiments were carried out with a Perkin Elmer Pyris I, with a $10 \pm 2 \mathrm{mg}$ sample on a temperature range of $50-900^{\circ} \mathrm{C}$, with $30^{\circ} \mathrm{C} / \mathrm{min}$ ramp rate under nitrogen atmosphere. TGA was coupled with an FTIR IFS66 Bruker Optics, in order to detect the evolved gases. The FTIR measurements were carried out in the range of $4000-400 \mathrm{~cm}^{-1}$, with 8 scans and spectral resolution of $1 \mathrm{~cm}^{-1}$.

\subsubsection{STEM}

Images of nanocomposites were obtained with a scanning transmission electron microscopy (STEM) detector coupled with a scanning electron microscope (SEM) (Quanta 200 SEM, FEI, Eindhoven, The Netherlands). All images were obtained under high vacuum at a voltage of $12.5-20 \mathrm{kV}$ with a spot size of $2-4 \mathrm{~mm}$ and a working distance of $6-10 \mathrm{~mm}$.

Table 1

Compositions of nanocomposites investigated and characteristics of nanoparticles used.

\begin{tabular}{|c|c|c|}
\hline Sample & Composition of the sample & Informations on the nanofillers given by the manufacturer \\
\hline 1 & PMMA & \\
\hline 2 & PMMA containing 0.2wt.\% MWNT & Multi-wall carbon nanotubes \\
\hline 3 & PMMA containing 1 wt.\% MWNT & Multi-wall carbon nanotubes \\
\hline 4 & PMMA containing nanofillers $15 w t . \% \mathrm{SiO}_{2}$ & Average primary particle size of $12 \mathrm{~nm}$ Surface aera $200 \mathrm{~m}^{2} / \mathrm{g}$ \\
\hline 5 & $\begin{array}{l}\text { PMMA containing nanofillers } 15 \mathrm{wt} . \% \mathrm{SiO}_{2} \text { with a } \\
\text { surface treatment (silane) }\end{array}$ & Average primary particle size of $12 \mathrm{~nm}$ Surface aera $150 \mathrm{~m}^{2} / \mathrm{g}$ \\
\hline 6 & PMMA with $15 w t . \%$ of APP & \\
\hline 7 & $\begin{array}{l}\text { PMMA containing nanofillers } 5 \mathrm{wt} . \% \mathrm{SiO}_{2} \text { with } \\
\text { 10wt.\% of APP }\end{array}$ & $\begin{array}{l}\text { Silica average primary particle size of } 12 \mathrm{~nm} \text { and APP } 2-13 \mu \mathrm{m} \text {.Silica } \\
\text { surface aera } 200 \mathrm{~m}^{2} / \mathrm{g} \text { and APP } 1.1 \mathrm{~m}^{2} / \mathrm{g}\end{array}$ \\
\hline 8 & $\begin{array}{l}\text { PMMA containing nanofillers } 5 \mathrm{wt} . \% \mathrm{SiO}_{2} \text { with a surface } \\
\text { treatment (silane) with } 10 \mathrm{wt} . \% \text { of APP }\end{array}$ & $\begin{array}{l}\text { Silica average primary particle size of } 12 \mathrm{~nm} \text { and APP } 2-13 \mu \mathrm{m} \text {.Silica } \\
\text { surface aera } 150 \mathrm{~m}^{2} / \mathrm{g} \text { and APP } 1.1 \mathrm{~m}^{2} / \mathrm{g}\end{array}$ \\
\hline 9 & PMMA containing nanofillers $15 w t . \% \mathrm{Al}_{2} \mathrm{O}_{3}$ & Average primary particle size of $13 \mathrm{~nm}$. Surface aera $100 \mathrm{~m}^{2} / \mathrm{g}$ \\
\hline 10 & $\begin{array}{l}\text { PMMA containing nanofillers } 15 \mathrm{wt} . \% \mathrm{Al}_{2} \mathrm{O}_{3} \text { with a } \\
\text { surface treatment (silane) }\end{array}$ & Average primary particle size of $13 \mathrm{~nm}$. Surface aera $100 \mathrm{~m}^{2} / \mathrm{g}$ \\
\hline 11 & $\begin{array}{l}\text { PMMA containing nanofillers } 5 \mathrm{wt} . \% \mathrm{Al}_{2} \mathrm{O}_{3} \text { with } \\
10 \mathrm{wt} . \% \text { of APP } \\
\text { PMMA containing nanofillers } 5 \mathrm{wt} . \% \mathrm{Al}_{2} \mathrm{O}_{3} \text { with a } \\
\text { surface treatment (silane) with } 10 \mathrm{wt} . \% \text { of APP }\end{array}$ & $\begin{array}{l}\text { Alumina average primary particle size of } 13 \mathrm{~nm} \text { and APP } 2-13 \mu \mathrm{m} \text {. } \\
\text { Alumina surface aera } 100 \mathrm{~m}^{2} / \mathrm{g} \text { and APP } 1.1 \mathrm{~m}^{2} / \mathrm{g} \\
\text { Alumina average primary particle size of } 13 \mathrm{~nm} \text { and APP } 2-13 \mu \mathrm{m} \text {. } \\
\text { Alumina surface aera } 100 \mathrm{~m}^{2} / \mathrm{g} \text { and APP } 1.1 \mathrm{~m}^{2} / \mathrm{g}\end{array}$ \\
\hline
\end{tabular}




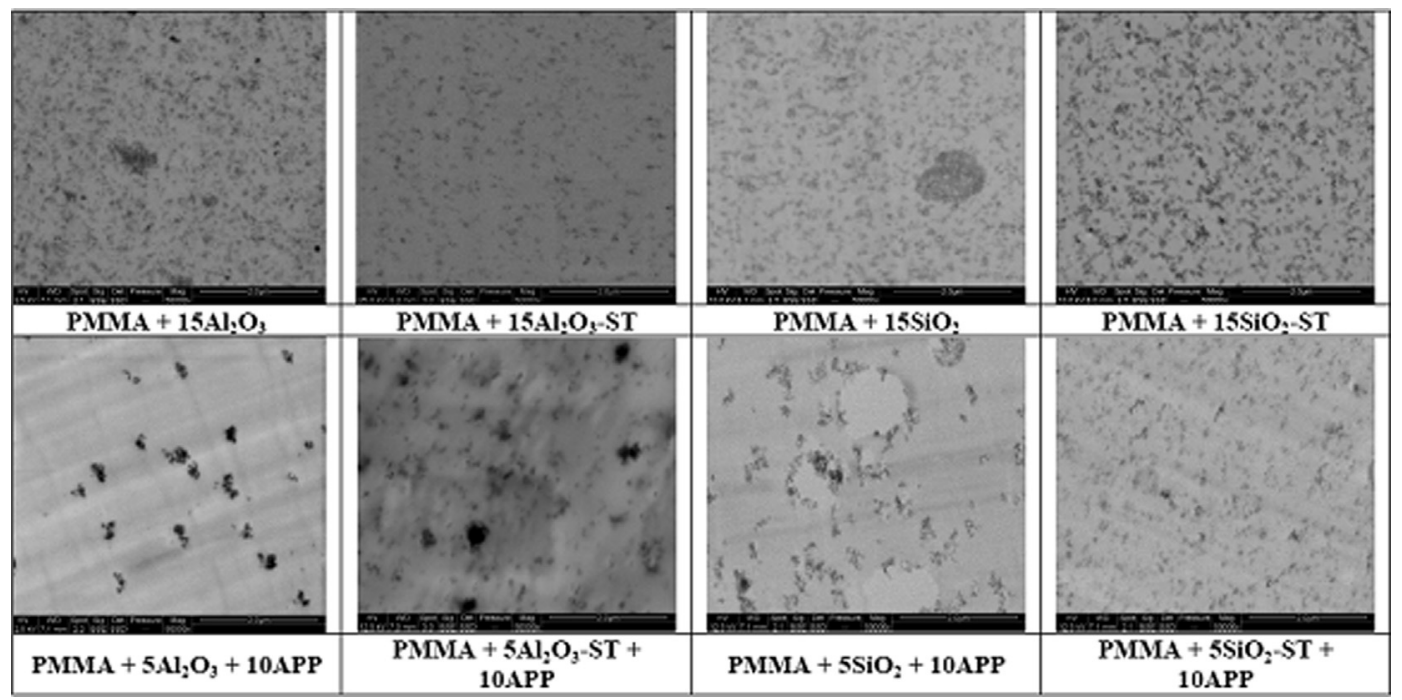

Fig. 2. Influence of APP on nanofillers with or without surface treatment (ST) dispersion by STEM analysis.

\subsection{4. $X$-rays diffraction}

X-Ray Diffraction (XRD) analyses of final residues were performed on a Bruker AXS D8 Advance diffractometer using $\mathrm{Cu} \mathrm{K} \alpha$ radiation.

\section{Results and discussions}

\subsection{Thermal degradation}

TGA-FTIR (thermo-oxidative conditions) was carried out to investigate the gas phase. This characterization allowed us to confirm that the thermal decomposition of PMMA pathway was not affected by the presence nanoparticles and APP. For all nanoparticles compositions containing only nanooxides, TGA curves are shifted towards higher temperatures, showing a better thermal stability in comparison with PMMA (Fig. 3) and particularly for treated nanoalumina. On the whole, the presence of APP tends to decrease the thermal stability, due to its partial decomposition from around $250{ }^{\circ} \mathrm{C}$. It can be observed that pristine PMMA leads to a complete decomposition through depolymerization. In all cases, the final residue is always lower for the treated nanoparticles. For compositions with both nanooxides and APP, the amount of residue is around $10-12 \mathrm{wt} \%$ of the original weight and should correspond to the formation of metallic phosphates.

Concerning absorbance analysis, the decomposition of PMMA and PMMA nanocomposites show only one series of bands corresponding to MMA (e.g. Fig. 4) during the short time of thermal degradation. Time values indicated by the red (in web version) and blue (in web version) arrows correspond respectively to the temperatures of 300 and $450{ }^{\circ} \mathrm{C}$.

All FTIR spectra, exemplified by spectra obtained at $450{ }^{\circ} \mathrm{C}$ (Fig. 5), show that there are only absorbance bands corresponding to neat PMMA degradation, i.e., the MMA bands. It can be concluded at small scale that silica, alumina, treated or not, APP, or the mix of APP and nanoparticles, do not influence the nature of gases released, only methyl methacrylate is formed. The dispersion of APP and nanofillers in polymer matrices seems not to have any effect on the gaseous composition from FTIR analysis. Nevertheless, it has to mention that using TGA/Mass spectroscopy, Laachachi [38] also identified a slight formation of acrylic acid. Conversely, the presence of nanooxides alone in PMMA leads to a residue, but in most cases, the percentage of nanoparticles remaining is below $15 \mathrm{wt} \%$, showing that a fraction of nanoparticles could have been emitted during TGA measurements. Obviously, particles cannot be detected by gas FTIR.
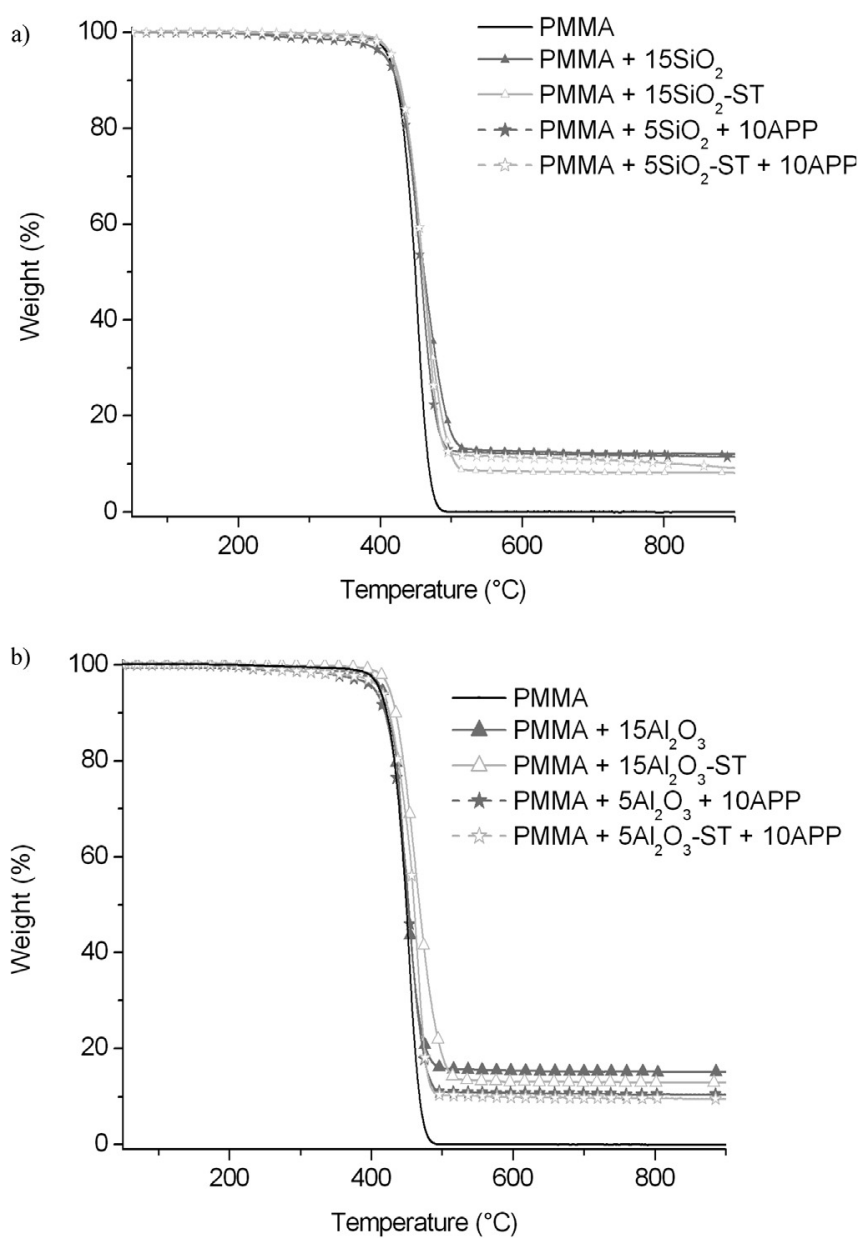

Fig. 3. Thermal degradation of neat and filled PMMA with silica (a) and alumina (b). 


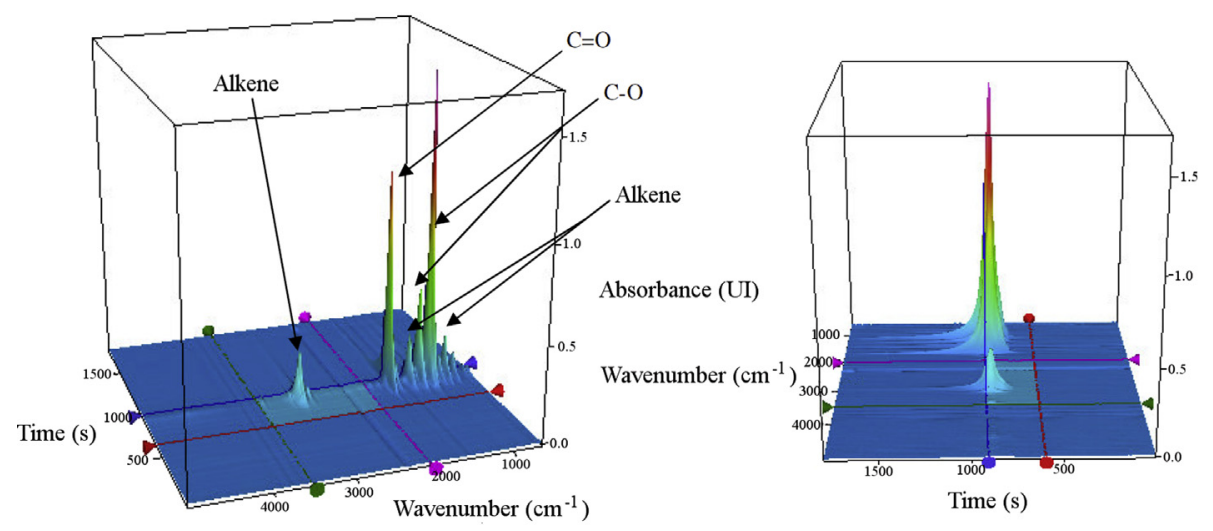

Fig. 4. Gas analyses of neat PMMA during thermal degradation by FTIR (3D: wavenumber, absorbance and time).

\subsection{Cone calorimeter tests and analysis of gaseous effluents}

The presence of 15\%wt nanofillers alone in PMMA reduces the HRR peak. The reduction of the HRR peak is of around $50 \%$ compared to virgin PMMA and it is attributed to the presence of nanofillers. The presence of $15 \mathrm{wt} \%$ nanofillers alone in PMMA reduces the HRR peak from 790 to $404 \mathrm{~kW} / \mathrm{m}^{2}$ for pristine silica, which is the lowest value. Both silica entail a better reduction in
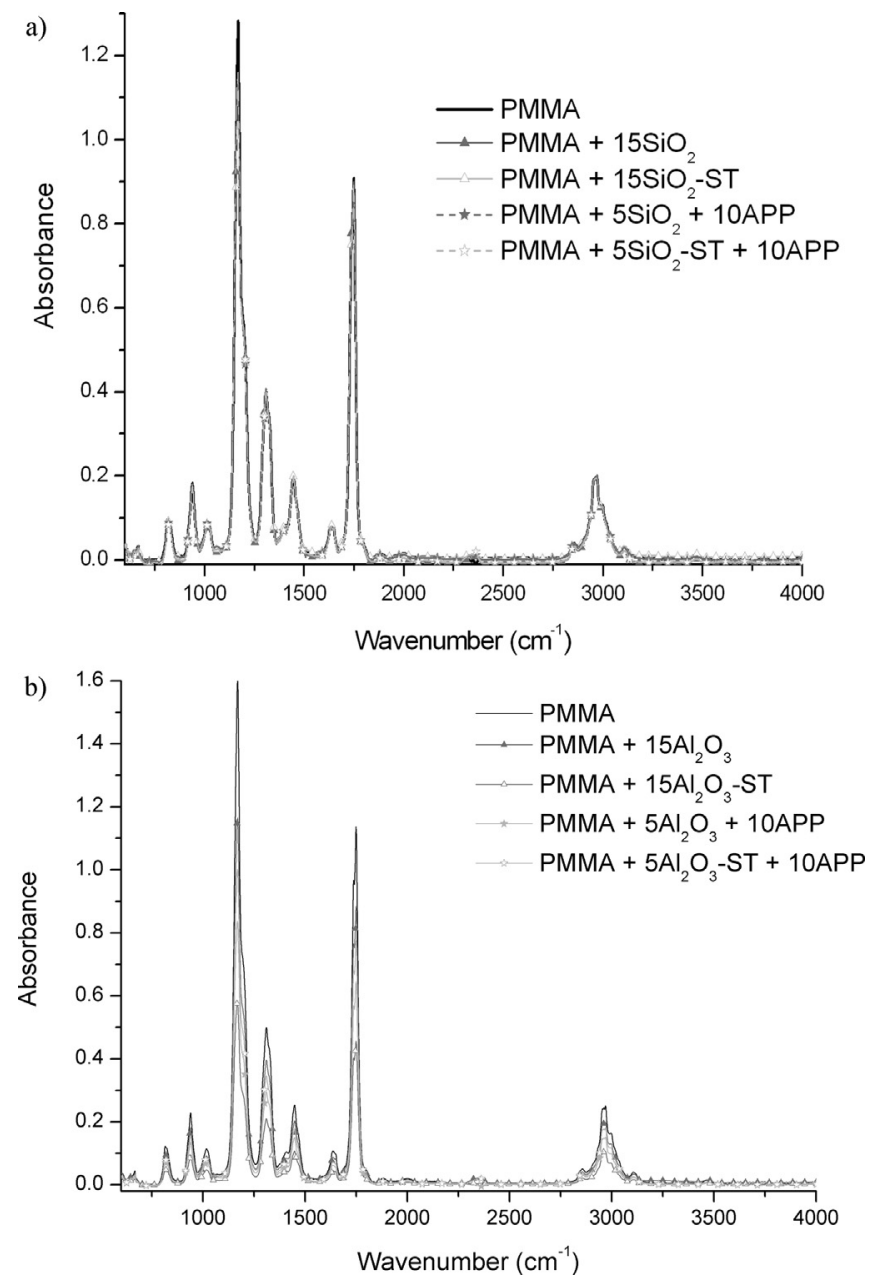

Fig. 5. FTIR spectra of neat PMMA and PMMA composites gases during thermal degradation with silica (a) and alumina (b). comparison with alumina. The substitution of $5 \mathrm{wt}$ \% of APP by nanooxide (silica or alumina) shows large effects on the fire retardant properties of PMMA. An improvement in the fire properties can be noticed by the incorporation of $15 \%$ wt. APP, $\mathrm{SiO}_{2}$ or $\mathrm{Al}_{2} \mathrm{O}_{3}$ (Table 2).

In combinations with APP, the better results are obtained with treated silica. The very low values of HRR obtained for this last composition (Table 2, Fig. 6) can be ascribed to a better dispersion of treated silica in PMMA which improves the reactivity with APP particles, leading to the formation of a silicon phosphate protective layer, highlighted in the work of Quach et al. [33].

The shape of the HRR curve and the time to ignition are also slightly modified in presence of treated silica (pHRR divided by 2) with a heat of combustion $(25.2 \pm 2.5 \mathrm{~kJ} / \mathrm{g})$ [39] on twice time duration.

In the case of nanoalumina compositions without APP, the HRR values corresponding to the percentage of $15 \mathrm{wt} \%$ lie between these of pristine and modified silica. For nanoalumina/APP compositions, there is no significant difference between pristine and modified alumina and the pHRR are higher than these observed for silica. But, only for silica compositions, it is possible to highlight a synergistic effect on pHRR between nanoparticles and APP.

On the whole, the mass loss rate of all silica compositions is lower than this of all other compositions (Table 2). The lowest value is obtained for the combination between modified silica and APP. Also a synergistic effect on final residue formation can be found for

Table 2

Combustion parameters obtained during experiment on cone calorimeter at $50 \mathrm{~kW} /$ $\mathrm{m}^{2}$.

\begin{tabular}{|c|c|c|c|c|c|}
\hline Sample & $\begin{array}{l}\text { pHRR } \\
\left(\mathrm{kW} / \mathrm{m}^{2}\right)\end{array}$ & $\begin{array}{l}\text { Time to } \\
\text { pHRR (s) }\end{array}$ & $\begin{array}{l}\text { Time of } \\
\text { CO peaks (s) }\end{array}$ & $\begin{array}{l}\text { Mass loss } \\
\text { rate } \\
\left(\mathrm{g} / \mathrm{m}^{2} / \mathrm{s}\right)\end{array}$ & $\begin{array}{l}\text { Residual } \\
\text { weight (\%) }\end{array}$ \\
\hline PMMA & 790 & 238 & 293 & 34 & 0 \\
\hline PMMA + APP & 661 & 185 & 290 & 30 & 8.0 \\
\hline $\mathrm{PMMA}+15 \mathrm{SiO}_{2}$ & 404 & 118 & 215 and 525 & 20 & 14.2 \\
\hline $\mathrm{PMMA}+15 \mathrm{SiO}_{2}-\mathrm{ST}$ & 426 & 118 & 275 and 385 & 19 & 13.4 \\
\hline $\begin{array}{l}\mathrm{PMMA}+5 \\
\mathrm{SiO}_{2}+10 \mathrm{APP}\end{array}$ & 337 & 125 & 340 and 400 & 25 & 10.1 \\
\hline $\begin{array}{l}\mathrm{PMMA}+5 \\
\quad \mathrm{SiO}_{2}-\mathrm{ST}+10 \mathrm{APP}\end{array}$ & 313 & 65 & $\begin{array}{l}265,345 \\
\text { and } 765\end{array}$ & 20 & 9.3 \\
\hline $\mathrm{PMMA}+15 \mathrm{Al}_{2} \mathrm{O}_{3}$ & 476 & 135 & 205 and 435 & 18 & 12.2 \\
\hline $\mathrm{PMMA}+15 \mathrm{Al}_{2} \mathrm{O}_{3}-\mathrm{ST}$ & 450 & 115 & 155 and 510 & 16 & 12.6 \\
\hline $\begin{array}{l}\mathrm{PMMA}+5 \\
\quad \mathrm{Al}_{2} \mathrm{O}_{3}+10 \mathrm{APP}\end{array}$ & 534 & 140 & 150 and 355 & 19 & 11.9 \\
\hline $\begin{array}{l}\mathrm{PMMA}+5 \\
\mathrm{Al}_{2} \mathrm{O}_{3}-\mathrm{ST}+10 \mathrm{APP}\end{array}$ & 524 & 155 & 275 and 345 & 15 & 15.2 \\
\hline
\end{tabular}




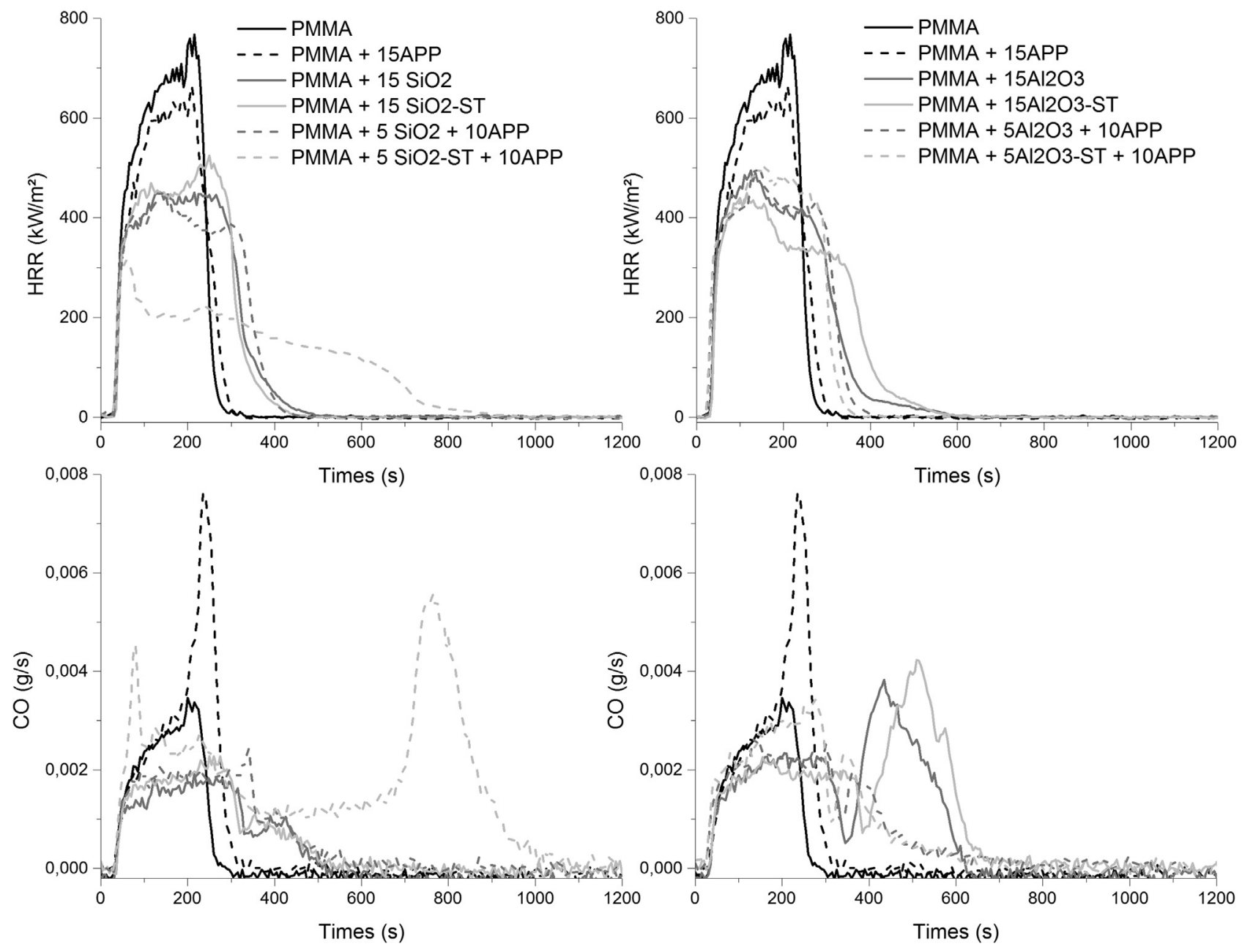

Fig. 6. Heat release rate and $\mathrm{CO}$ emission rate as function of time for silica-based compositions and for alumina-based compositions.

both silica/APP compositions, the composition with modified silica leading to the highest weight of residue.

All the results are in accordance with these of Quach et al. [33] obtained in the same conditions of irradiance and those of Cinausero [27], but for an irradiance of only $35 \mathrm{~kW} / \mathrm{m}^{2}$.

The evolution of the gaseous effluents emitted during combustion was measured with the FTIR/cone calorimeter coupling.

$\mathrm{CO}, \mathrm{CO}_{2}$, and $\mathrm{NO}$ are plotted as a function of time for an external heat flux equal to $50 \mathrm{~kW} / \mathrm{m}^{2}$ in Figs. 6 to 10.

It can be noticed that all compositions containing nanoparticles exhibit very different $\mathrm{CO}$ emission rates in comparison with pure PMMA.

While pure silica compositions tends to reduce the peak of CO emission and to delay its emission in comparison with pristine PMMA, alumina compositions which show a similar profile up to 300 s lead afterwards to a strong $\mathrm{CO}$ emission peak in a range which correspond to a near complete decomposition of the composite.

The incorporation of APP results in a strong and sharp CO emission peak which is slightly shifted in comparison with pHRR. Consequently, it can be interpreted as a consequence of a poorventilated combustion due to the formation of a protective layer formed at the surface of the residue at the end of the combustion.

The combination between pristine alumina and APP lead to intermediate $\mathrm{CO}$ yields in comparison with the effects of each component. Modified alumina seems more interesting since a plateau-shaped curve is obtained at a similar maximum value as this of alumina alone, but without a secondary emission peak higher than the maximum value at the plateau.

For pristine silica combined with APP, a similar behaviour as $\mathrm{APP} /$ alumina compositions is observed, but the plateau value is higher. Conversely, APP/modified silica composition exhibits a CO

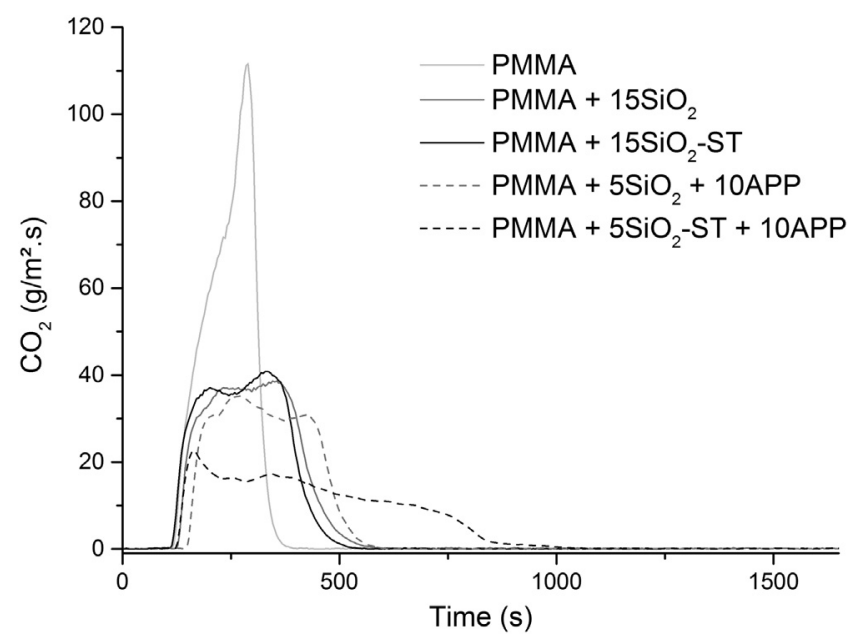

Fig. 7. $\mathrm{CO}_{2}$ emission rate as function of time for silica-based compositions. 


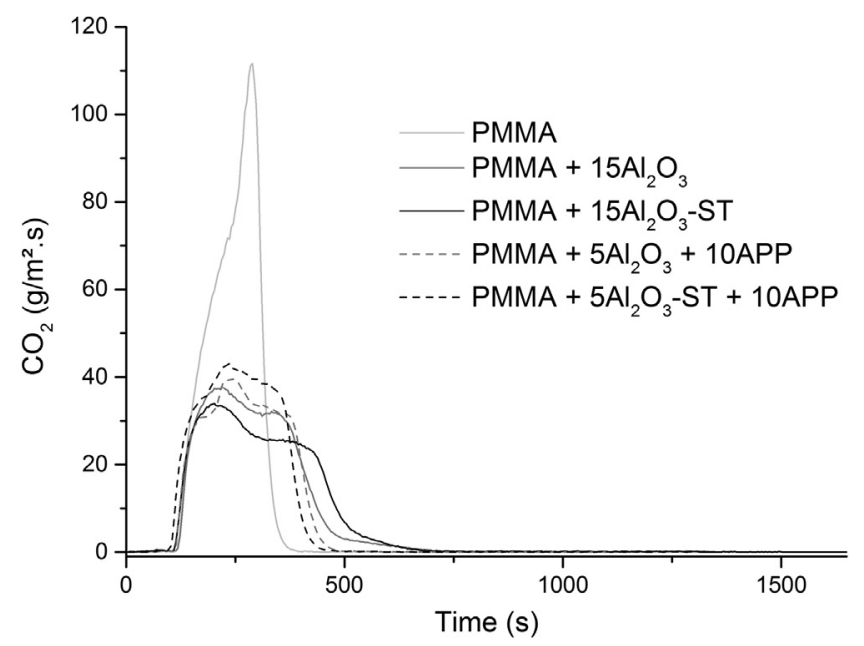

Fig. 8. $\mathrm{CO}_{2}$ emission rate as function of time for alumina-based compositions.

emission curve which coincides with the HRR curve for the first stages of decomposition. Hence, it can be considered that the decrease of $\mathrm{CO}$ emission after this peak is due to the formation of the protective layer in the case of combinations with APP. The char builds an insulating layer between the residual material and the heat source, creating a barrier to $\mathrm{O}_{2}$ diffusion. The formation of this layer leads to a poor-ventilated combustion at the residual polymer/layer interface, resulting in a relatively strong CO emission, particularly at the end of the combustion, also possibly due to a cracking of the protective layer, and leading to a secondary $\mathrm{CO}$ emission peak due to char pyrolysis. This second peak is particularly high, suggesting an intensive process of pyrolysis of the protective layer which presents the higher residue retained for all compositions (Table 2). Conversely, for the same composition, the emission of $\mathrm{CO}_{2}$ is much lower than this of the other compositions. This confirms that the combustion for PMMA $+\mathrm{SiO}_{2}-\mathrm{ST}+10 \mathrm{APP}$ is strongly under-ventilated.

The emission of NO is lesser for the compositions with the nanoparticles alone in comparison with pristine PMMA. Conversely, peaks of NO emission are 4 times higher than this of PMMA for APP/nanoalumina compositions as well as for APP/ pristine silica composition and 3 times higher for APP/modified silica composition. It can be noticed that the corresponding emission curve for this last composition is strongly correlated to the $\mathrm{CO}$

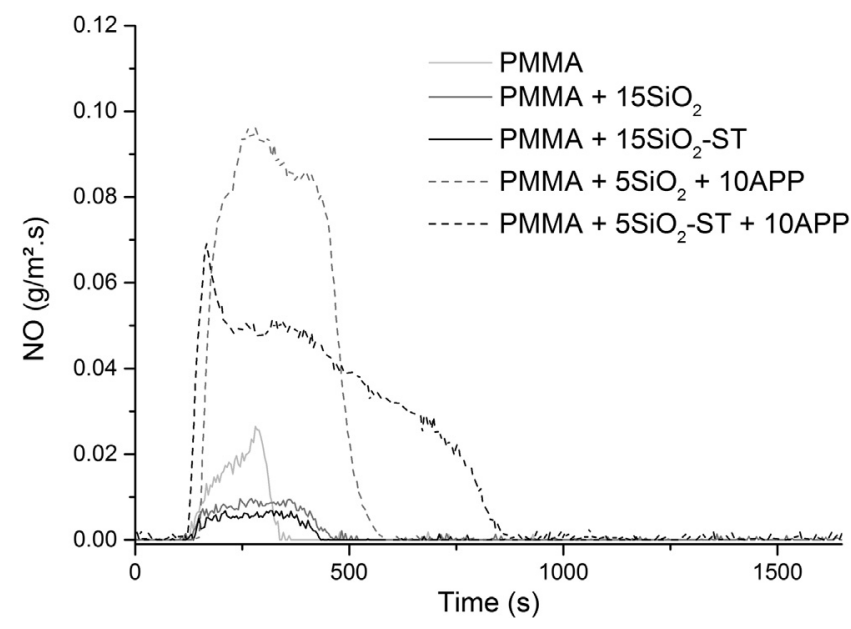

Fig. 9. NO emission rate as function of time for silica-based compositions.

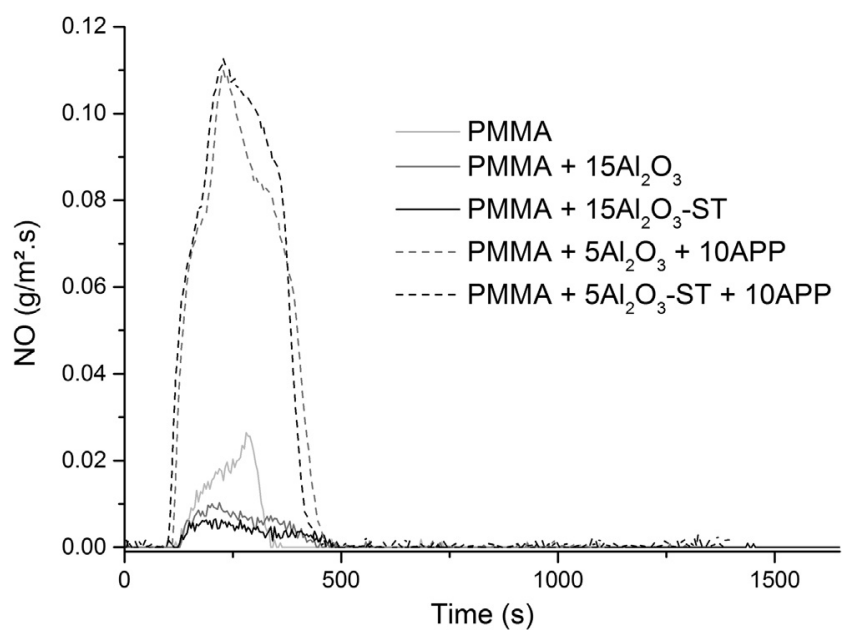

Fig. 10. NO emission rate as function of time for alumina-based compositions.

emission curve up to 500s. Moreover, a correlation also exists with the production of cyanhydric acid (Fig. 11). Formation of nitrogen oxide is explained by oxidation of ammonia (evolved during APP decomposition) which is known to take place at high temperatures $[40,41]$. But in case of PMMA, the small amount $(<0.6 \mathrm{mg} / \mathrm{g})$ of $\mathrm{NO}_{x}$ formation seems to be ascribed to the oxidation of nitrogen regardless of the irradiance level considered fixed at $50 \mathrm{~kW} / \mathrm{m}^{2}$. This is in accordance with the paper of Kilpinen [42] which mentions the formation of thermal $\mathrm{NO}_{x}$ based on the oxidation of nitrogen from the air and dominant at high temperature. Except for PMMA - $5 \mathrm{Al}_{2} \mathrm{O}_{3}-\mathrm{ST}-10 \mathrm{APP}$ compositions, the presence of $\mathrm{HCN}$ is recorded as soon as the thermal degradation of PMMA/nanofillers for ammonium polyphosphate-based formulations (APP) starts, but it can be quantified only for PMMA - $5 \mathrm{SiO}_{2}-\mathrm{ST}-10$ APP. Nevertheless, it seems that on the one hand, ammonia $\left(\mathrm{NH}_{3}\right)$ coming from ammonium polyphosphate burns during the gaseous phase; on the other hand the hypothesis on the formation of HCN in small quantities as soon as combustion starts can be explained by an oxyamination reaction between $\mathrm{CH}_{4}$ or $\mathrm{CH}_{3}-\mathrm{OH}$ (PMMA) and $\mathrm{NH}_{3}$ (APP) with a reaction temperature of about $750{ }^{\circ} \mathrm{C}$, according to the following reaction: $\mathrm{CH}_{4}+\mathrm{NH}_{3}+3 / 2 \mathrm{O}_{2} \rightarrow \mathrm{HCN}+3 \mathrm{H}_{2} \mathrm{O}$ (Andrussow process, [43]). This comes from the equilibria mentioned in Fig. 12.

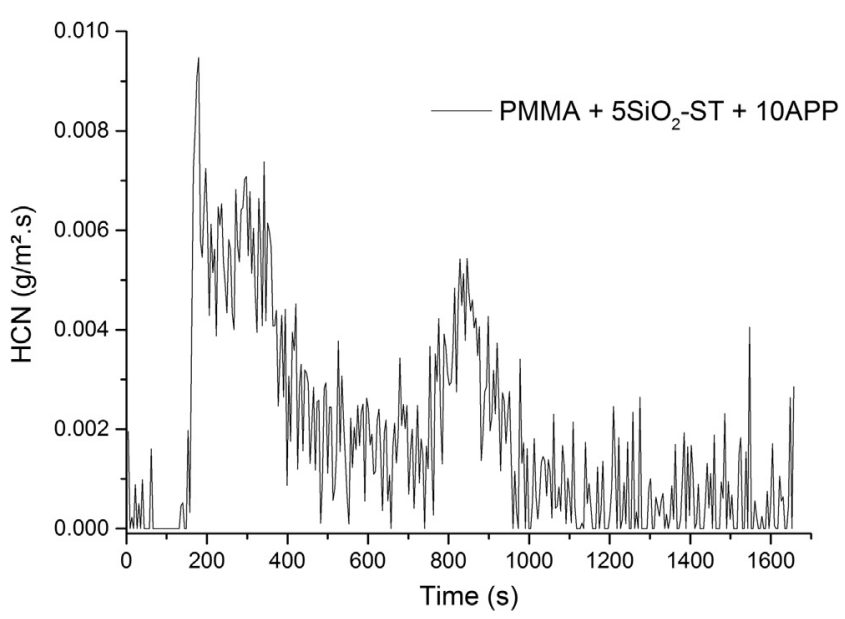

Fig. 11. HCN emission rate as function of time for modified silica/APP composition. 


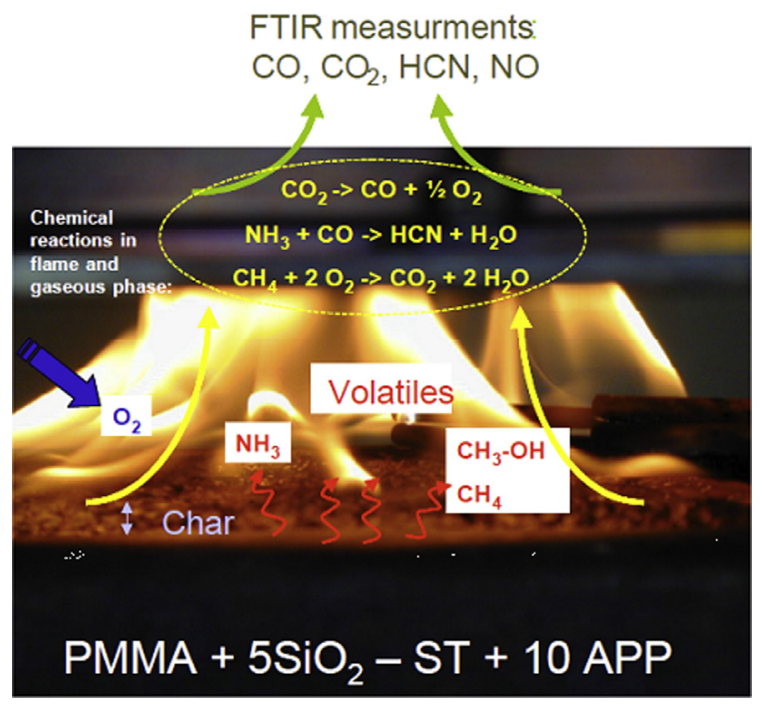

Fig. 12. Illustration of the suggested mechanisms in gaseous phase within the flame leading to the apparition of NO and HCN in smokes.

Table 3 summarizes the results from FTIR analysis coupled to the cone calorimeter tests, concerning the emissions of combustion gases issued from the two PMMA containing oxide (silica or alumina) based nanofillers.

Traces of $\mathrm{NH}_{3}$ are present to the outbreak of the combustion, leading to $\mathrm{NO}$ emission. Traces of $\mathrm{NH}_{3}$ are also released at the end of the combustion.

Detection limits of the analysers are $1.0 \mathrm{ppm}$ for $\mathrm{CO}, \mathrm{HCN}$ and NO and $100 \mathrm{ppm}$ for $\mathrm{CO}_{2}$. Considering the typical mass of the samples, this corresponds to approximately $0.5 \mathrm{mg} / \mathrm{g}$ for CO, HCN and NO, and $70 \mathrm{mg} / \mathrm{g}$ for $\mathrm{CO}_{2}$.

$\mathrm{CO}$ yields for accidental fire conditions are approximatively similar for all PMMA samples, excepted for PMMA -5 $\mathrm{SiO}_{2}-\mathrm{ST}-10$ APP where carbon monoxide yield is higher than the other formulations.

Even if the presence of fire retardant (APP) and the incorporation of nanosilica with a surface treatment reduce the flammability. The surface treatment on silica nanoparticles contributes to the

Table 3

Emission rate of gaseous effluents in $\mathrm{mg} / \mathrm{g}(\mathrm{mg} / \mathrm{g}$ of burn product) from PMMA formulations with nano-objects.

\begin{tabular}{|c|c|c|c|c|c|}
\hline \multirow[t]{3}{*}{ Sample } & \multicolumn{5}{|l|}{ Gas } \\
\hline & \multicolumn{5}{|c|}{ Emitted gas rate in mg by gram of burnt material } \\
\hline & $\begin{array}{l}\text { Carbon } \\
\text { monoxide } \\
(\mathrm{CO})\end{array}$ & $\begin{array}{l}\text { Carbone } \\
\text { dioxide } \\
\left(\mathrm{CO}_{2}\right)\end{array}$ & $\begin{array}{l}\text { Nitrogen } \\
\text { oxide } \\
\text { (NO) }\end{array}$ & $\begin{array}{l}\text { Cyanhydric } \\
\text { acid (HCN) }\end{array}$ & $\begin{array}{l}\text { Ammonia } \\
\left(\mathrm{NH}_{3}\right)\end{array}$ \\
\hline PMMA & 11 & 2581 & 0.6 & 0 & 0 \\
\hline PMMA - APP & 13 & 1820 & 5.0 & 0 & $0.17-0.54$ \\
\hline PMMA - $15 \mathrm{SiO}_{2}$ & 11 & 2142 & 0.5 & 0 & 0 \\
\hline $\mathrm{PMMA}-15 \mathrm{SiO}_{2}-\mathrm{ST}$ & 10 & 2101 & 0.3 & 0 & 0 \\
\hline $\begin{array}{l}\mathrm{PMMA}-5 \\
\mathrm{SiO}_{2}-10 \mathrm{APP}\end{array}$ & 12 & 1974 & 5.3 & $\mathrm{~T}$ & 0 \\
\hline $\begin{array}{l}\mathrm{PMMA}^{-5} \\
\mathrm{SiO}_{2}-\mathrm{ST}-10 \mathrm{APP}\end{array}$ & 42 & 1816 & 5.2 & 0.7 & 0 \\
\hline $\mathrm{PMMA}-15 \mathrm{Al}_{2} \mathrm{O}_{3}$ & 21 & 2004 & 0.4 & 0 & 0 \\
\hline $\begin{array}{l}\text { PMMA - } 15 \\
\quad \mathrm{Al}_{2} \mathrm{O}_{3}-\mathrm{ST}\end{array}$ & 21 & 2023 & 0.2 & 0 & 0 \\
\hline $\begin{array}{l}\text { PMMA - } 5 \\
\qquad \mathrm{Al}_{2} \mathrm{O}_{3}-10 \text { APP }\end{array}$ & 15 & 1967 & 4.6 & $\mathrm{~T}$ & 0 \\
\hline $\begin{array}{l}\mathrm{PMMA}-5 \\
\quad \mathrm{Al}_{2} \mathrm{O}_{3}-\mathrm{ST}-10 \mathrm{APP}\end{array}$ & 18 & 1987 & 4.9 & 0 & 0 \\
\hline
\end{tabular}

formation of a compact structure during smoke emission. The high value of the $\mathrm{CO}$ yield could lead to the conclusion that the above combination could affect the risk of toxicity. But, the nanocomposite based on APP and surface modified silica delays the CO yield emission. This phenomenon could permit people evacuate buildings or houses in case of fire.

\subsection{Morphology and analysis of residues and smoke emission}

Fig. 13 shows the different structures of residues obtained. The residues containing silica seems more cohesive than these with alumina, even without APP.

Moreover, the overall structure of the residue PMMA $+5 \%$ $\mathrm{SiO}_{2}+10 \%$ APP is different than that of PMMA $+5 \% \mathrm{SiO}_{2}-\mathrm{ST}+10 \%$ APP. In the former residue, the charred layer is crumbly, whereas the latter has a charred shield, which is continuous and expanded. Cohesion of residue is higher and can limit the rate of release of gases. The structure of the residue is organized in stacked layers for the entire volume of the charred structure. This structure exhibits large voids, allowing a good heat isolation of the material and reducing its degradation rate. It protects the unburnt sample underneath from the heat flux, and modifies the oxygen supply conditions, leading to a rapid rise of $\mathrm{CO}$ production and a longer duration for the test (see Table 2). The duration of evolving $\mathrm{CO}$ seems directly linked to the cracking of the residual structure.

Clear differences of residue (for PMMA/APP $/ \mathrm{SiO}_{2}$ versus for PMMA/APP/ST $\mathrm{SiO}_{2}$ ) and residual mass (at the end, $15.2 \%$ without surface treatment versus $11.9 \%$ for $\mathrm{PMMA} / \mathrm{APP} / \mathrm{SiO}_{2}$ ) were identified.

The morphology of the external char structure is characterized by an irregular surface ("small islands") for PMMA/APP $/ \mathrm{SiO}_{2}$ that can explain the liberation of gaseous during all the combustion. Conversely, homogeneous structure in presence of the silica surface treatment by comparing the samples that can explain the barrier effect. Nevertheless, at the end of combustion, a blooming structure increases the pressure on the char and induces liberation of $\mathrm{CO}$.

Similar silicon phosphate structures $\left(\mathrm{SiP}_{2} \mathrm{O}_{7}\right)$ as found by Yen et al. [33] were identified. For aluminium-based compositions, different aluminium phosphate structures were identified in the residue by Cinausero et al. [27] for an irradiance of $35 \mathrm{~kW} / \mathrm{m}^{2}$. It was ascribed to the surface treatment, and its influence on particle dispersion, able to play a role on the reactivity between the components. Nevertheless, it can also be assumed that the silane treatment could itself play a role on reactivity.

To address this issue, XRD analyses of mixtures $\mathrm{APP}+\mathrm{Al}_{2} \mathrm{O}_{3}$ and $\mathrm{APP}+\mathrm{Al}_{2} \mathrm{O}_{3}-\mathrm{ST}$ (ratio 2:1 and without PMMA matrix), heated at $500{ }^{\circ} \mathrm{C}$ for $5 \mathrm{~min}$, were also performed and compared to the structures analysed in the residues. The XRD analyses (Fig. 14) showed $\mathrm{AlPO}_{4}$ crystalline phase is always present, showing no specific influence of octylsilane surface treatment for irradiance of $50 \mathrm{~kW} / \mathrm{m}^{2}$

Smoke performance of flame retardant nanocomposites is a significant parameter in fire safety fields. The Rate of Smoke Release and Total Smoke Released as function of time of all samples are illustrated Fig. 15 and Fig. 17.

When comparing the effect of APP on TSR, the presence of APP in PMMA increases significantly the smoke emission as compared with pristine PMMA which mainly releases methyl methacrylate. The presence of silica alone leads to a very close emission level as pristine PMMA and it is even slightly delayed.

An overview of the potential toxicity of nanocomposite [44] has recently done using AFM as a complementary tool for measuring the aerosol from combustion. 


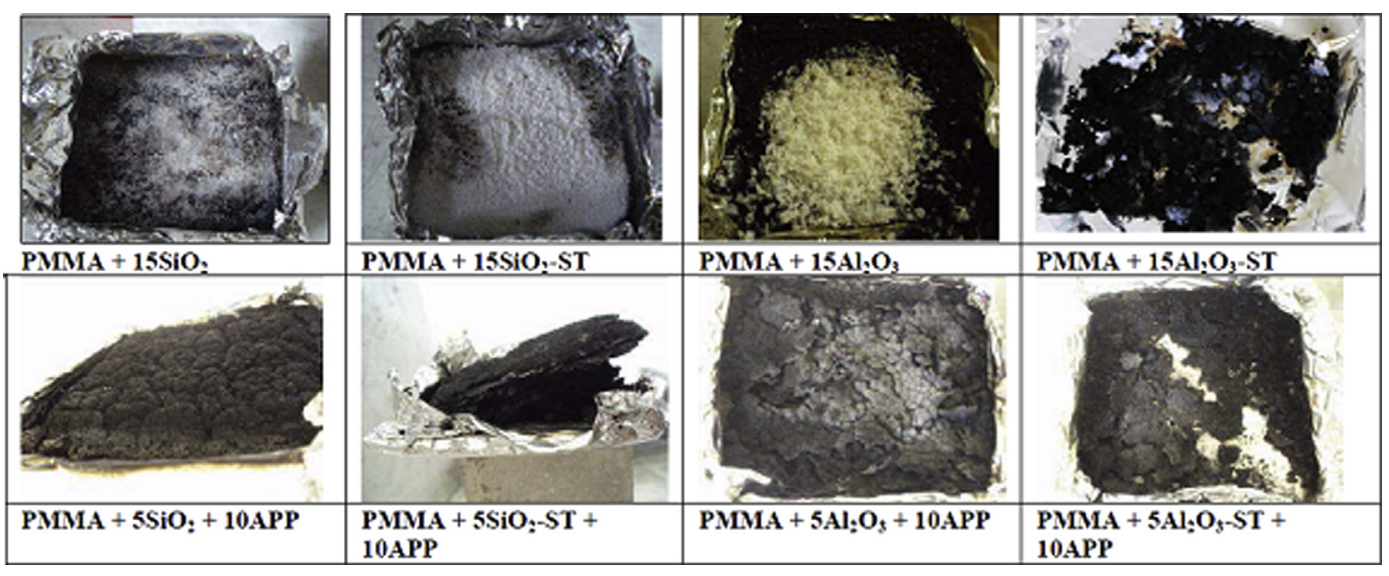

Fig. 13. Carbonaceous layer formed on top of the PMMA according to the formulations.

It has been shown by various studies [35,45], that particles with a diameter less than $4 \mu \mathrm{m}$ and can penetrate into the lungs. The particles lesser than $2 \mu \mathrm{m}$ are likely to be deposited deeply in the lung tissue, in the bronchioles. Finer particles around $0.5 \mu \mathrm{m}$ can penetrate the alveoli.

Hence, particles with a diameter between 0.5 and $4 \mu \mathrm{m}$ present a higher risk of absorption due to their propensity to penetrate the bodies of the human respiratory tract.

Fig. 16 shows the morphology of nano-aerosol with a cut-off diameter $\left(D_{50 \%}\right)$ at $1.6 \mu \mathrm{m}$ that is different from usual fractal form of carbon aerosols.

This aerosol is similar to a more compact structure. One hypothesis explaining this morphology is the presence of silane on nanoparticles of silica that have fixed soot of carbon on the surface to create this compact structure. They are constituted by elementary particles (with a median diameter size of $40 \mathrm{~nm}$ ). The agglomerated structure, on filter, forms complex structures in the micronic range. These particles are sometimes included into an oily phase (tar).

In the case of alumina nanoparticles, opposite to silica, more impact on soot production is noted, and this can be connected to a

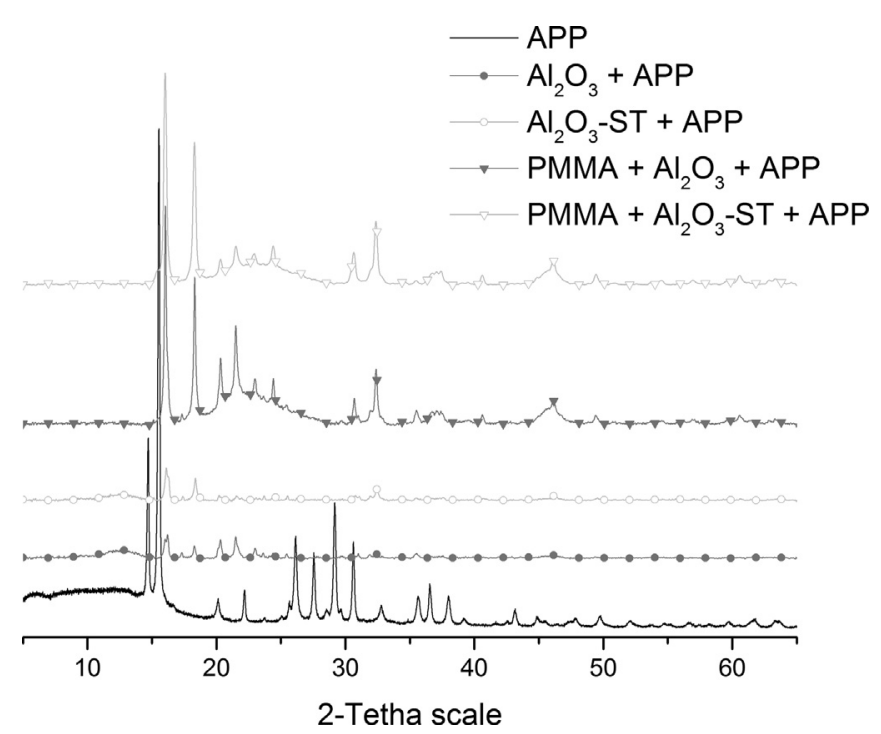

Fig. 14. X-ray diffraction patterns of APP, $5 \mathrm{Al}_{2} \mathrm{O}_{3}+10$ APP, $5 \mathrm{Al}_{2} \mathrm{O}_{3}-\mathrm{ST}+10$ APP, PMMA $-5 \mathrm{Al}_{2} \mathrm{O}_{3}-10 \mathrm{APP}-\mathrm{ST}$, and PMMA - $5 \mathrm{Al}_{2} \mathrm{O}_{3}-10$ APP. highest mass loss rate for aluminium-based compositions in comparison to silica-based ones.

All the combinations with APP lead to intermediate values of smoke emission between APP and nanooxides alone. It can be concluded that nanooxide have a specific effect to reduce smoke production in the combustion process of PMMA/APP. For both kinds of nanoparticles, highest TSR values are noticed for modified oxides. The highest TSR value is observed for the modified silica/APP composition, but one has to notice that the main contribution occurs around 70s and coincides with the first peak of CO emission, which means that an underventilated combustion took place, but without the formation of a cohesive layer at this stage of the degradation. The protection of the carbon layer induces a reduction of combustible gases and smoke-forming materials in the gas phase during combustion. The RSR curve present many irregularities from 200s which can be attributed to the formation of cracks in the protective layer.

\section{Conclusions}

The fire behaviour of PMMA has a significant improvement after incorporating FR and modified nanoparticles.

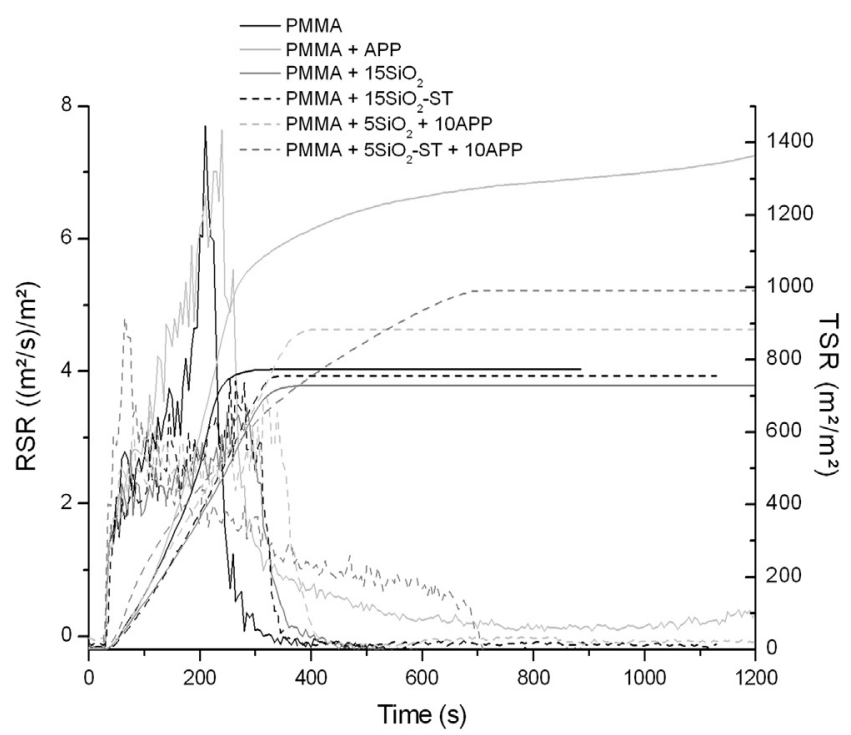

Fig. 15. Rate of Smoke Release and Total Smoke Released as function of time for silicabased compositions. 


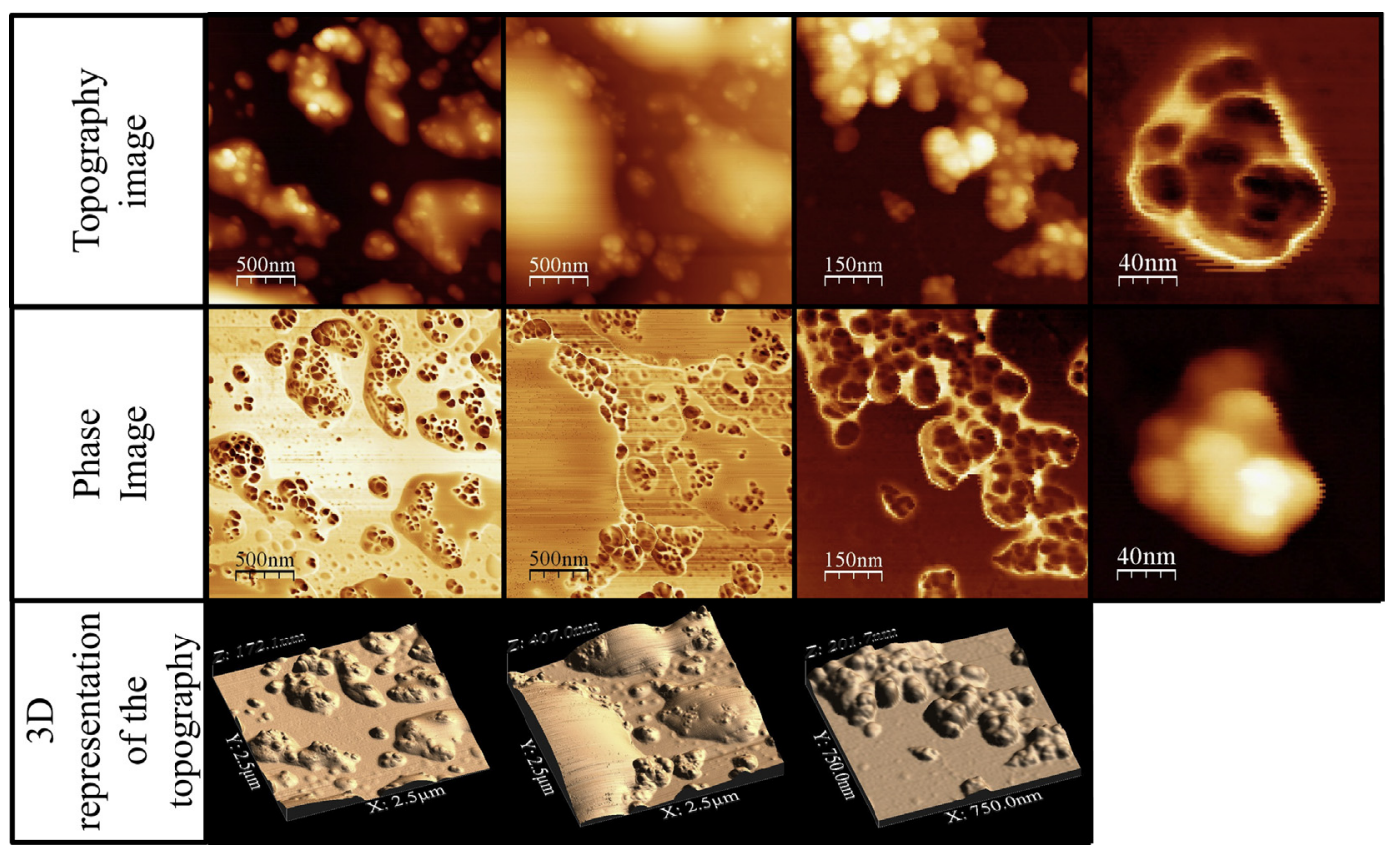

Fig. 16. AFM images of the soot obtained after combustion of the mixture PMMA $+5 \mathrm{SiO}_{2}-\mathrm{ST}+10 \mathrm{APP}$.

No influence on the degradation pathway of composites was noticed. The composition of the evolving gases during the decomposition of the nanocomposites is not modified by the incorporation of nanoxides. The use of nanooxides with surface treatment, combined or not with ammonium polyphosphate in PMMA does not lead to a significant modification of gases emitted during combustion.

Nevertheless, the kinetics of gas emission depends on the nature of the formulation, particularly for APP/nanooxide compositions with the formation of a char at the surface of nanocomposites. While the surface treatment has no influence for alumina compositions, in the case of silica compositions, the use of an octylsilane treatment seems more effective than no modification. In this work,

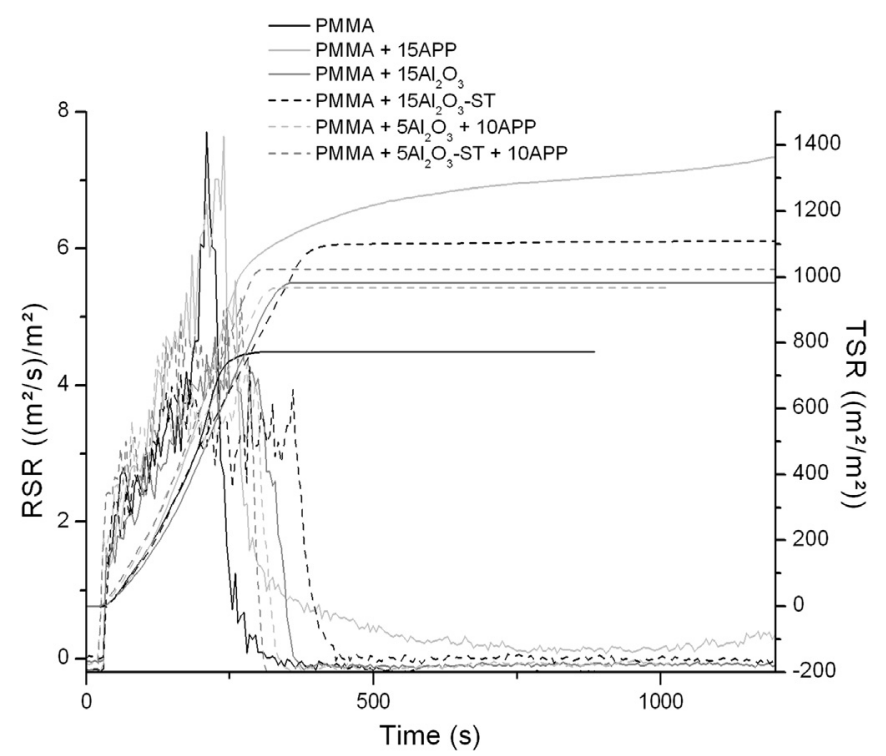

Fig. 17. Rate of Smoke Release and Total Smoke Released as function of time for aluminium-based compositions. the variation of thermal degradation behaviour induced by silica nanoparticles is mainly attributed to the combination of the following effects:

- a very cohesive and expanded charred structure containing silicon pyrophosphate is formed which reduces the HRR values.

- a synergistic effect between APP and nanosilica is observed. It is ascribed to a better dispersion of treated silica in PMMA, which allows a better reactivity with APP; however, this entails an underventilated combustion with measurable emission of $\mathrm{HCN}$ and higher amounts of $\mathrm{CO}$ emission, particularly at the end of the combustion.

\section{Acknowledgements}

Thanks to the French Research Agency (ANR) for the financial support provided for the NANOFEU project. Thanks to the partnership of the project with manufacturers in the industry (PLASTICSEUROPE), we were able to select and obtain carbon nanotubes, as well as nanocomposite materials. Thanks to all NANOFEU partners (LNE, EMA, ISMANS, INERIS and PlasticsEurope) for their collaboration in this project. We would sincerely thank S.Buonomo, B.Gallard and L.Dumazert from EMA for their technical support. And thanks to S. Ducourtieux from LNE for his expertise in AFM technology.

\section{References}

[1] Lopez-Cuesta JM, Laoutid F. Multicomponents FR systems polymer nanocomposites combined with additional materials. Chap. 12. In: Wilkie C, Morgan A, editors. Fire retardancy of polymeric materials. CRC press; 2010.

[2] http://ec.europa.eu/nanotechnology/index_en.html, view the 24.07.2013.

[3] Polymethyl methacrylate (PMMA) market by application, grade \& form global trends \& forecasts $(2012$ - 2017). July 2012. www.marketsandmarkets. com. Report Code: AD 1177.

[4] Kashiwagi T, Inaba A, Brown JE, Hatada K, Kitayama T, Masuda E. Effects of weak linkages on the thermal and oxidative degradation of poly(methyl methacrylates). Macromolecules 1986;19:B2160-8.

[5] Manring LE. Thermal degradation of poly(methyl methacrylate). 2. Vinylterminated polymer. Macromolecules 1989;22:2673-7. 
[6] Manring LE. Thermal degradation of poly(methylmethacrylate). 4. Random side-group scission. Macromolecules 1991;24:3304-9.

[7] Bounekhel M, McNeill IC. Preparation and thermal degradation studies of telechelic poly(methyl methacrylate). Polym Degrad Stab 1999;65:443-8.

[8] Ferriol M, Gentilhomme A, Cochez M, Oget N, Mieloszynski JL. Therma degradation of poly(methyl methacrylate) (PMMA) : modelling of DTG and TC curves. Polym Degrad Stab 2003;79:271-81.

[9] Peterson JD, Vyazovkin S, Wight CA. Kinetics of the thermal and thermooxidative degradation of polystyrene, polyethylene and poly(propylene). Macromol Chem Phys 2001;202:775-84.

[10] Kashiwagi T, Inaba A. Behavior of primary radicals during thermal degradation of poly(methyl methacrylate). Polym Degrad Stab 1989;26:161-84.

[11] Brown JE, Kashiwagi T. Gas phase oxygen effect on chain scission and monomer content in bulk poly(methyl methacrylate) degraded by external thermal radiation. Polym Degrad Stab 1996;52:1-10.

[12] Holland BJ, Hay JN. The kinetics and mechanisms of the thermal degradation of poly(methyl methacrylate) studied by thermal analysis-Fourier transform infrared spectroscopy. Polymer 2001;42:4825-35.

[13] Holland BJ, Hay JN. The effect of polymerisation conditions on the kinetics and mechanisms of thermal degradation of PMMA. Polym Degrad Stab 2002;77: 435-9.

[14] Kashiwagi T, Du F, Winey KJ, Groth KM, Shields JR, Bellayer SP, et al. Flammability properties of polymer nanocomposites with singled-walled carbon nanotubes: effects of nanotube dispersion and concentration. Polymer 2005; $46: 471-81$.

[15] Wang H, Xu P, Zhong W, Shen L, Du Q. Transparent poly(methyl methacrylate)/silica/zirconia nanocomposites with excellent thermal stabilities. Polym Degrad Stab 2005;87:319-27.

[16] Morgan AB, Antonucci JM, Van Landingham MR, Harris RH, Kashiwagi T. Thermal and flammability properties of a silica-PMMA nanocomposite. Polym Mater Sci Eng 2000;83:57-67.

[17] Lee Yi-Mu, Viswanath DS. Degradation of poly(methyl methacrylate) (PMMA) with aluminum nitride and alumina. Polym Eng Sci 2000;40:2332-41.

[18] Marinović-Cincović M, Popović MC, Novaković MM, Nedeljković JM. The influence of $\beta-\mathrm{FeOOH}$ nanorods on the thermal stability of poly (methyl methacrylate). Polym Degrad Stab 2007;92:70-4.

[19] Yang F, Nelson GL. Polymer/silica nanocomposites prepared via extrusion Polym Adv Technol 2006;17:320-6.

[20] Yang F, Bogdanova I, Nelson GL. Impact of the chemical composition of nanofillers on the flammability of polymer nanocomposites. Polym Adv Technol 2008;19:602-8.

[21] Cai G, Lu H, Zhou Y, Hao J, Wilkie CA. Fire retardancy of emulsion polymerized poly (methyl methacrylate)/cerium(IV) dioxide and polystyrene/cerium(IV) dioxide nanocomposites. Thermochim Acta 2012;549:124-31.

[22] Laachachi A, Leroy E, Cochez M, Ferriol M, Lopez Cuesta JM. Use of oxide nanoparticles and organoclays to improve thermal stability and fire retardancy of poly(methyl methacrylate). Polym Degrad Stab 2005;89:344-52.

[23] Laachachi A, Ferriol M, Cochez M, Ruch D, Lopez-Cuesta J-M. The catalytic role of oxide in the thermooxidative degradation of poly(methyl methacrylate)$\mathrm{TiO}_{2}$ nanocomposites. Polym Degrad Stab 2008;93:1131-7.

[24] Laachachi A, Cochez M, Leroy E, Gaudon P, Ferriol M, Lopez Cuesta JM. Effect of $\mathrm{Al}_{2} \mathrm{O}_{3}$ and $\mathrm{TiO}_{2}$ nanoparticles and APP on thermal stability and flame retardance of PMMA. Polym Adv Technol 2006;17:327-34.

[25] Laachachi A, Cochez M, Ferriol M, Lopez-Cuesta JM, Leroy E. Influence of TiO and $\mathrm{Fe}_{2} \mathrm{O}_{3}$ fillers on the thermal properties of poly(methyl methacrylate) (PMMA). Mater Lett 2005;59:36-9.

[26] Cinausero N, Azema N, Lopez Cuesta JM, Cochez M, Ferriol M. Impact of modified alumina oxides on the fire properties of PMMA and PS nanocomposites. Polym Adv Technol 2011;22:1931-9.
[27] Cinausero N, Azema N, Lopez-Cuesta J-M, Cochez M, Ferriol M. Synergistic effect between hydrophobic oxide nanoparticles and ammonium polyphosphate on fire properties of poly(methyl methacrylate) and polystyrene. Polym Degrad Stab 2011;96:1445-54.

[28] Liufu S-C, Xiao H-N, Li Y-P. Thermal analysis and degradation mechanism of polyacrylate/ZnO nanocomposites. Polym Degrad Stab 2005;87:103-10.

[29] Grohens Y, Auger M, Prud'homme R, Schultz J. Adsorption of stereo-regular, poly(methyl methacrylates) on alpha-alumina: spectroscopic analysis. J Polym Sci Part B: Polym Phys 1999;37:2985-95.

[30] Laachachi A, Cochez M, Leroy E, Ferriol M, Lopez-Cuesta JM. Fire retardant systems in poly(methyl methacrylate): interactions between metal oxide nanoparticles and phosphinates. Polym Degrad Stab 2007;92:61-9.

[31] Friederich B, Laachachi A, Sonnier R, Ferriol M, Cochez M, Toniazzo V, et al. Comparison of alumina and boehmite in (APP/MPP/metal oxide) ternary systems on the thermal and fire behavior of PMMA. Polym Adv Technol 2012;23:1369-80.

[32] Wang X, Wu L, Li J. Synergistic flame retarded poly(methyl methacrylate) by nano- $\mathrm{ZrO}_{2}$ and triphenylphosphate. J Therm Analysis Calorim 2011;103: 741-6.

[33] Quach Y, Cinausero N, Sonnier R, Longuet C, Lopez-Cuesta J-M. Barrier effect of flame retardant systems in poly(methylmethacrylate): study of the efficiency of the surface treatment by octylsilane of silica nanoparticles in combination with phosphorous fire retardant additives. Fire Mater 2012;36: 590-602.

[34] Motzkus C, Chivas-Joly C, Guillaume E, Ducourtieux S, Saragoza L, Lesenechal D, et al. Aerosols emitted by the combustion of polymers containing nanoparticles. J Nanoparticle Res 2012;14:687-705.

[35] Rhodes J, Smith C, Stec AA. Characterisation of soot particulates from fire retarded and nanocomposite materials, and their toxicological impact. Polym Degrad Stab 2011:96:277-84.

[36] ISO 5660-1. Reaction to fire tests - heat release, smoke production and mass loss rate - part 1: heat release rate (cone calorimeter method). 2002.

[37] ISO 19702. Analysis of fire gases using fourier infrared technique- FTIR. 2004.

[38] Laachachi A. PhD dissertation. France: Université de Lorraine; 2005.

[39] Chivas-Joly C, Motzkus C, Guillaume E, Ducourtieux S, Saragoza L, Lesenechal D, et al. Influence of carbone nanotubes on fire behaviour and aerosols emitted during combustion of thermoplastics. Fire Mater 2014;38: 46-62.

[40] Hunyadi D, Sajó I, Miklós Szilágyi I. Structure and thermal decomposition of ammonium metatungstate. J Therm Analysis Calorim 2014;116:329-37.

[41] Madarász J, Miklós Szilágyi I, Hange F, Pokol G. Comparative evolved gas analyses (TG-FTIR, TG/DTA-MS) and solid state (FTIR, XRD) studies on thermal decomposition of ammonium paratungstate tetrahydrate (APT) in air. J Anal Appl Pyrolysis 2004:72:197-201.

[42] Kilpinen P, Kallio S, Konttinen J, Barisic V. Char-nitrogen oxidation under fluidised bed combustion conditions: single particle studies. Fuel 2002;81: 2349-62.

[43] Rase HF, Ammoxidation. In: Handbook of commercial catalysts: heterogeneous catalysts. CRC Press; 2000. p. 48-53 [Chapter 4].

[44] Lopez-Cuesta JM, Longuet C, Chivas-Joly C. Health and environmental safety of nanomaterials: polymer nancomposites and other materials containing nanoparticles. Thermal degradation, flammability, and potential toxicity of polymer nanocomposites. 2014. p. 278-310 [Chapter 13].

[45] Oberdörster G, Maynard A, Donaldson K, Castranova V, Fitzpatrick J, Ausman K, et al., A report from the ILSI Research Foundation/Risk Science Institute Nanomaterial Toxicity Screening Working Group. Principles for characterizing the potential human health effects from exposure to nanomaterials: elements of a screening strategy. Part Fibre Toxicol 2005 2:8. 